\title{
A vida na universidade: vozes de licenciandos de um curso de Ciências Biológicas ${ }^{1,2}$ \\ Life in the university: voices of graduates of a course in Biological Sciences
}

\author{
Daisi Teresinha Chapani (dt.chapani@gmail.com.br). \\ Universidade Estadual do Sudoeste da Bahia. \\ Programa de Pós-graduação em Educação Científica e Formação de Professores. \\ Jaqueline Trindade Araújo (jtaraujo1@ hotmail.com ). \\ Universidade Estadual do Sudoeste da Bahia. \\ Programa de Pós-graduação em Educação Científica e Formação de Professores \\ Aiala Silva Souza (aialassouza@ hotmail.com). \\ Universidade Estadual do Sudoeste da Bahia. \\ Programa de Pós-graduação em Educação Científica e Formação de Professores
}

\section{Resumo:}

Esse trabalho é o resultado de um estudo que busca compreender como se desenvolve a vida universitária de estudantes de licenciatura em ciências biológicas de uma universidade pública no interior da Bahia. Partimos das expressões contidas nas respostas de 95 estudantes a um questionário e nos depoimentos, obtidos por meio de entrevista, de 18 deles. Ao imprimirmos nesse material nosso esforço interpretativo e o entrelaçarmos com resultados de outros estudos, tecemos um metatexto que, em linhas gerais, segue certa cronologia, evidenciando a entrada e a vivência no curso. A abordagem utilizada nos possibilitou melhor conhecer esses estudantes, para além das possibilidades oferecidas por categorias homogeneizantes, que são insuficientes para captar as singularidades dos licenciandos como pessoas.

Palavras-chave: vida de estudante; formação docente; licenciatura.

\begin{abstract}
This paper is the result of a study that seeks to understand how the university life of undergraduate students in biological sciences of a public university in the interior of Bahia is developed. We start from the expressions contained in the responses of 95 students to a questionnaire and by the testimony of 18 of them, obtained through an interview. When we print it our interpretive effort and interweave it with results from other studies, we weave a metatext that, in general terms, follows a chronological order related to the entrance and the experience in the course. The approach used enabled us to better know these students, beyond the possibilities offered by homogenizing categories, which are insufficient to capture the singularities of the graduates as people
\end{abstract}

Key Words; student life; teacher training; graduation.

\section{INTRODUÇÃO}

\footnotetext{
${ }^{1}$ Trata-se de versão revista e ampliada de trabalho submetido ao XII ENPEC

${ }^{2}$ Apoio parcial: Capes
} 
Quando se procura conhecer os estudantes dos cursos de licenciaturas, geralmente traça-se um perfil dos mesmos, enquadrando-os em grandes categorias, como classe social, gênero, raça, situação laboral, grupo familiar etc. (MASSI; VILLANI, 2014; MAZZETTO; SÁ CARNEIRO, 2002; PIRES et al, 2014; VASCONCELOS; LIMA, 2010). Estudos deste tipo são importantes porque jogam luz sobre uma série de características e similaridades do licenciandos, que podem servir para subsidiar políticas estudantis e estratégias acadêmicas visando a democratização do ensino superior, por meio da promoção da entrada, da permanência e da melhoria do rendimento acadêmico e da formação profissional de mais pessoas de diferentes origens sociais e culturais.

Porém, quando analisadas isoladamente, essas categorias podem tornar-se homogeneizantes, impedindo-nos de melhor conhecer aqueles que frequentam esses cursos nas suas especificidades e distinções. Por isso, consideramos importante acrescentar a esse panorama elementos mais sutis, que nos permitam compreender as singularidades desses estudantes.

Tal empreendimento torna-se ainda mais premente nesse momento em que as universidades, tanto no Brasil quanto em outros países, passam por mudanças no público que as compõem, relativas ao gênero, idade, interesses, perfil socioeconômico e grupo social de origem (COULON, 2017; SAMPAIO, 2011; SCHLEICH; POLYDORO; SANTOS, 2006; SOUZA; SANTOS, 2014). Porém, conforme advertem os autores citados, o aumento do número de estudantes no ensino superior e de sua heterogeneidade não foi acompanhado por uma preocupação das instituições em melhor conhecê-los.

Além disso, destacamos o movimento que desde meados do século XX vem ocorrendo no campo da formação docente, que busca valorizar as múltiplas dimensões da do professor, incluindo suas vivências e experiências, sejam elas diretamente relacionadas à profissão ou aquelas mais amplas de sua história de vida (ANDRÉ, et al., 1999; NÓVOA, 1992; SLONGO; DELIZOICOV; ROSSET, 2010). Conforme a literatura tem destacado (NÓVOA, 1992; TARDIF; RAYMOND, 2000), a constituição da pessoa do professor decorre de experiências várias que precede seu ingresso na profissão.

No entanto, aspectos relacionados à subjetividade, aos desejos e à afetividade são pouco abordados na literatura brasileira sobre formação inicial de professores de ciências, sendo geralmente considerados em estudos que se utilizam de narrativas (auto) biográficas na formação/autoformação docente (BREMM; GÜLLICH, 2018; GASTAL; 
AVANZI, 2015). No âmbito da vivência universitária de diferentes cursos, esses aspectos são usualmente tratados no contex to da qualidade de vida e saúde dos estudantes (ASSIS; OLIVEIRA, 2011), de satisfação acadêmica (SCHLEICH; POLYDORO; SANTOS, 2006), na compreensão dos motivos para evasão do curso (BARDAGI; HUTZ, 2012) e nos estudos da vida universitária (SAMPAIO, 2011).

Desse modo, o objetivo desse trabalho é colaborar com essa discussão, buscando a compreensão de como se desenrola a vida universitária de estudantes de um curso de licenciatura em ciências biológicas de uma universidade pública no interior da Bahia, por meio de suas expressões a respeito do que experienciam durante sua formação.

Entendemos que se a instituição formadora conhecer melhor seus estudantes, para além do rendimento acadêmico e dos estereótipos, poderá fomentar um ambiente mais humano, favorecendo a permanência e o sucesso dos alunos e colaborando para formar pessoas mais seguras com relação a si mesmas e atentas às necessidades do outro, mais envolvidas academicamente e capazes de tomar decisões a respeito de sua vida pessoal e profissional com mais segurança.

\section{REFERENCIAL TEÓRICO}

$\mathrm{O}$ aumento do número de estudantes no ensino superior e a exigência social pela democratização desse nível de ensino têm estimulado a pesquisa a respeito da vida e do ofício dos estudantes (SAMPAIO, 2011; COULON, 2017), uma vez que, conforme afirmam Souza e Santos (2014, p. 68): "as questões que envolvem a afiliação e a permanência na universidade ultrapassam o desafio do acesso à educação superior, incluem a adaptação à universidade, a sua rotina, seus rituais e normas”.

Ao ingressar na universidade, os jovens veem-se na premência de desenvolver modos de agir, habilidades e práticas que são próprios da cultura acadêmica, sejam relacionados às aulas e às atividades de preparação profissional, seja com relação à instituição e suas normas ou às formas de interações entre colegas, professores e funcionários (SOUZA, SANTOS, 2014).

Em nosso país, os "novos públicos" que tem chegado à universidade são oriundos de classes populares, sendo que muitos jovens são os primeiros de sua família a ingressar nesse ambiente (SAMPAIO, 2011; SOUZA, SANTOS, 2014). Nas licenciaturas, esse fenômeno não é exatamente novo, visto que esses cursos, geralmente menos concorridos 
e oferecidos no turno da noite, são tradicionalmente a porta de entrada dos alunos trabalhadores para a educação superior. De modo que, se para os jovens em geral, a transição do ensino médio para a universidade se configura em um desafio, mais ainda para quem:

nem sequer tem estabelecida uma rede de contatos com pessoas já inseridas no ensino superior, em muitos casos é o primeiro representante de sua família a ingressar na universidade. Não tem ideia de como a universidade funciona, do que é requisitado aos estudantes na vida universitária (SOUZA, SANTOS, 2014).

Para Almeida, Soares e Ferreira (2000), o processo de transição e adaptação à universidade é bastante complexo, envolvendo diferentes variáveis, as quais influenciamse mutuamente e interferem na maneira como os estudantes se adaptam e se desenvolvem no ensino superior. Segundo esses autores, ao adentrar a universidade, o estudante enfrenta desafios em quatro diferentes domínios: acadêmico, social, pessoal e vocacional.

Nesse sentido, a entrada e os primeiros meses na universidade são especialmente críticos, de maneira que as pesquisas geralmente enfocam o momento de transição do ensino médio para a universidade, sendo mais raros estudos ligados à experiência universitária ao longo do curso (OGUSHI; BARDAGI, 2015). No entanto, durante sua vida universitária, o estudante passa por diferentes situações que tanto podem ser prazerosas e consideradas positivas para o seu desenvolvimento acadêmico e pessoal, quanto podem ser estressantes e desmotivadoras.

No campo da formação docente, Tardif e Raymond (2000) chamam atenção para a diversidade de espaços e tempos que concorrem para a constituição dos saberes docentes, que são caracterizados como plurais, compósitos e heterogêneos, sendo fortemente influenciado pelo tempo, estando, portanto, inscritos na história de vida do professor.

Assim, os saberes doentes são constituídos também pelo que se desenvolve na universidade durante a formação inicial do professor. Enfatizamos, porém, que não apenas o aprendizado de conteúdos teóricos-práticos relativos à profissão colabora na constituição destes saberes, mas também as diversas vivências e experiências pelas quais os estudantes passam durante sua vida universitária.

\section{METODOLOGIA}

A pesquisa foi realizada com estudantes de licenciatura do curso de ciências biológicas, do campus de Jequié, da Universidade Estadual do Sudoeste da Bahia. O curso 
apresenta as modalidades de licenciatura e de bacharelado. A estrutura curricular da licenciatura atende ao disposto na Resolução CNE/CP 02/2015 e se constitui de disciplinas de formação geral (Anatomia, Biologia Celular, Ecologia, Fisiologia Humana, Botânica etc.) e de formação profissional específica (Didática, Estrutura e Funcionamento da Educação Básica, Psicologia da Educação, Metodologia e Prática de Ensino etc), além de atividades de complementação curricular. São ofertadas anualmente 30 vagas no período noturno e 20 no diurno. Possui regime acadêmico semestral e presencial e a matrícula é feita por disciplina. Sua estrutura permite que o aluno do turno diurno integralize o curso em 4 anos e do noturno em 4,5 anos (UESB, 2011).

A pesquisa utilizou-se de uma abordagem qualitativa, conforme Lüdke e André (2012), pois trata-se de um esforço de compreensão dos significados, impressões e valores atribuídos pelos licenciandos à sua vivência universitária, buscando compreender as particularidades e as experiências individuais produzidas no contexto sócio histórico.

Os dados foram obtidos no quadro de duas pesquisas de mestrado: uma sobre a permanência dos estudantes no curso até sua conclusão e outra sobre a participação dos licenciandos em atividades extracurriculares, em ambas os instrumentos foram elaborados com a finalidade de oferecer uma perspectiva contextualizada dos dados, de maneira que, em conjunto, eles nos oferecem uma visão ao mesmo tempo panorâmica e aprofundada da universidade pelo olhar dos alunos. A fim de distinguir o instrumento utilizado, os dados foram identificados por meio da letra " $E$ ", se foi extraído de entrevista, ou " $Q$ " se for resposta de um questionário + a letra "A" se foi obtido no projeto sobre atividades extracurriculares e "P" se foi obtido no contexto do projeto sobre permanência.

No primeiro semestre de 2018 havia 225 alunos matriculados no curso, sendo que 95 deles (67 do noturno e 28 do diurno) nos devolveram preenchido um formulário contendo suas respostas a questões abertas, referentes à sua caracterização pessoal e vivência no curso. Os participantes tinham idade entre 18 a 62 anos, sendo que 54 deles declararam-se do sexo feminino, 40 do sexo masculino e um não se identificou. Entre os respondentes havia um aluno cego e um surdo. Também foram realizadas entrevistas semiestruturadas com 18 estudantes, pertencentes ao mesmo grupo.

Devido à restrição de espaço, detalhamos a caracterização apenas dos participantes citados neste trabalho, usando nomes fictícios, conforme Quadro 1: 
Quadro 1: Codimone e características dos estudantes citados no texto:

\begin{tabular}{|c|c|c|c|}
\hline Codinome & Idade (anos) & Semestre & turno \\
\hline Ailton & 29 & dessemestralizado & noturno \\
\hline Alex, & 30 & $5^{\circ}$ & noturno \\
\hline Angel & 23 & $3^{\circ}$ & noturno \\
\hline Caio & 22 & $7^{\circ}$ & diurno \\
\hline Daniel & 27 & $8^{\circ}$ & noturno \\
\hline Dédalo & 23 & dessemestralizado & diurno \\
\hline Dilma & 29 & $7^{\circ}$ & noturno \\
\hline Edna & não informado & $7^{\circ}$ & noturno \\
\hline Elson, & 20 & $6^{\circ}$ & noturno \\
\hline Fabrícia, & 26 & $7^{\circ}$ & diurno \\
\hline Fox & 23 & $7^{\circ}$ & diurno \\
\hline Iago & 22 & $9^{\circ}$ & noturno \\
\hline Iraldo & 22 & $7^{\circ}$ & noturno \\
\hline Jacy & 27 anos & dessemestralizada & diurno \\
\hline Jason & não informado & $7^{\circ}$ & noturno \\
\hline July & 26 & $9^{\circ}$ & noturno \\
\hline José & 36 & $6^{\circ}$ & noturno \\
\hline Katia & 22 & $6^{\circ}$ & noturno \\
\hline Lara & 27 & dessemestralizada & noturno \\
\hline Leide & 25 & $7^{\circ}$ & noturno \\
\hline Lucy & 25 & dessemestralizada & noturno \\
\hline Luna & 23 & dessemestralizada & diurno \\
\hline Marta & 21 & $5^{\circ}$ & diurno \\
\hline Matias & 20 & $6^{\circ}$ & diurno \\
\hline Maura & 21 & $5^{\circ}$ & diurno \\
\hline Miguel & 22 & $9^{\circ}$ & noturno \\
\hline Odessa & 24 & $7^{\circ}$ & noturno \\
\hline Paola & não informado & $8^{\circ}$ & diurno \\
\hline Teo & 38 & $8^{\circ}$ & noturno \\
\hline Valda & 29 & dessemestralizada & noturno \\
\hline Valdir & 56 & $7^{\circ}$ & noturno \\
\hline Vicente & 21 & $6^{\circ}$ & noturno \\
\hline
\end{tabular}

A análise foi realizada tomando-se os pressupostos da Análise Textual Discursiva (ATD), em que primeiro realizamos uma leitura atenta de todo o material (constituído pelas respostas ao questionário e pelas transcrições das entrevistas), a fim de encontramos as unidades de sentido que foram utilizadas para a fragmentação dos textos. Devido à maneira como as questões foram apresentadas nos instrumentos, o corpus de análise evidenciou narrativas com marcadores temporais claros, o que nos levou a elaborar um metatexto que obedeceu a certa cronologia, destacando alguns trechos de depoimentos que evidenciam os aspectos que consideramos mais relevantes em nossa análise. A tessitura do metatexto incorporou tanto os depoimentos dos participantes quanto nossas 
interpretações sobre os mesmos e os resultados de outras pesquisas que tratam da formação e professores de ciências e da vida universitária.

\section{RESULTADOS E DISCUSSÕES}

Nessa seção apresentamos o metatexto resultante da análise, subdividido em dois tópicos: a entrada e a vivência no curso.

\section{1 - A entrada: anseios, desejos, escolhas, dificuldades, adaptação}

Para os participantes da pesquisa, as razões para a busca da universidade estiveram relacionadas principalmente com os anseios de emprego e mobilidade social. Por exemplo, Iraldo nos disse que: "na minha família poucas pessoas tiveram a oportunidade de estar na universidade, então, eu queria pelo menos ter frequentado o ambiente" (EA), enquanto Jason narrou a seguinte situação: "eu tinha aquela visão: 'quando terminar ensino médio, eu vou trabalhar'. E eu fui trabalhar em um depósito, descarregando saco de cimento, e eu morava lá, no depósito. E eu fui vendo que você precisa ter ensino superior, tem que ter um estudo. Eu tenho que estudar, não tem outra solução, para quem sabe, amanhã ou depois, poder dar uma melhor vida para o meu pai e minha mãe" (EP).

Os participantes indicaram que escolheram o curso de ciências biológicas por razões bastante diversas. Algumas vezes o curso não era a primeira opção, como por exemplo, nos informa Lucy: "na verdade, eu sempre quis algum curso na área de saúde. Tentei enfermagem, fisioterapia, medicina, mas não alcançava pontuação suficiente. Enfim, optei por biologia pensando que já estando dentro da universidade, facilitaria o meu processo para ingressar em um curso de saúde." (QA). Iago explica o processo de exclusão que ele realizou até decidir pelo curso de ciências biológicas: "minha primeira opção de escolha de curso foi história, mas aí eu via muita gente falando que era um curso que não tinha retorno, então, acabei não indo, até porque ia gerar uma despesa muito grande morar em outra cidade. Aí eu fiz um descarte: eu não gostava muito da área de saúde porque associava com a sangue, também não gostava da área das exatas porque associava tudo a cálculo, então, biologia foi o que eu me identifiquei no momento de fazer a escolha" (EP). A jornada de Miguel também é um exemplo das complexas razões que levam os estudantes a optar por um curso: "na verdade, eu nunca tive uma vocação, eu sai do ensino médio com 16 anos e optei por matemática, que era dos cursos que tinha menos concorrência. Eu entrei em matemática, era bem tranquilo, mas aí, na 
segunda metade do curso, eu comecei a me complicar bastante. Eu estava dando aulas durante o dia e estudava à noite e comecei a me complicar no curso. Na época, eu namorava uma menina que fazia biologia e que estava gostando do curso, e a minha opção sempre foi noturno, porque que eu trabalhava. Então, aí surgiu essa questão de mudar para biologia e eu acabei optando, não me arrependo não" (EP).

Outros alunos, no entanto, afirmaram que escolheram o curso porque gostavam dos assuntos relacionados à biologia, como nos conta Ailton: "sempre me atraiu, a área de biologia, então, o que mais me motivou foi esse gosto pessoal pelo curso, não foi nem pela área de trabalho ou pelas oportunidades que me daria de fácil acesso, mas pelo gosto mesmo" (EP). Valda nos disse: "sempre fui apaixonada pela biologia, tenho fascínio pela natureza, eu sempre quis estudar todas questões biológicas que estão a nossa volta e entender como elas funcionam" (QA). Valdir buscou o curso em função trabalho que já desenvolve: "eu trabalho com abelhas sem ferrão e com sistemas agroflorestais, por isso a escolha foi em função da minha zona de atuação" (QA).

A entrada na licenciatura deu-se por motivos diversos, porém contou muito o fato de ser oferecido no noturno e pelos estudantes considerar que teriam mais chances de trabalho que no bacharelado. Gatti (2010) afirma que a escolha pela licenciatura, muitas vezes, é uma espécie de "seguro desemprego", uma vez que supostamente oferecem maiores oportunidades ocupacionais e poderiam garantir um trabalho, caso não se consiga exercer outra profissão. Nesse sentindo, Angel nos disse: "escolhi por ser menos concorrido e pelo fato de ser uma licenciatura, acredito que terei mais oportunidades de emprego" (QA), enquanto para July: “a licenciatura não foi uma opção por gostar da área, mas sim por ser noturno e não oferecer o bacharelado” (QA).

Alguns depoimentos mostraram que, a despeito das pesquisas que indicam a pouca atratividade da carreira docente (GATTI, 2009), há aqueles que buscam a licenciatura porque querem ser professores, como por exemplo, Matias disse: "o meu desejo sempre foi ser professor. E ser professor de biologia iria permitir que eu apresentasse aos alunos o quão perfeito é o nosso planeta" (QA), da mesma forma José afirma: "sempre quis estar inserido em uma sala de aula como professor". Outros depoimentos nos permitem apurar que esse desejo pode ser incentivado pela família ou por professor do ensino médio, como por exemplo, quando Marta disse: "meus pais são professores, eu sempre gostei de licenciatura e realmente eu me vejo sendo professora de crianças, de adolescentes, 
mesmo ainda querendo ensinar na faculdade" (EA) e Iraldo afirma: "tive muitos professores bons que, para mim, são os verdadeiros heróis. O contato com eles me fez ter o desejo de seguir a carreira e poder contribuir com a sociedade por meio da educação" (QA).

Contudo, as disposições iniciais podem se alterar no decorrer do curso, como podemos notar na fala de Marta: "a licenciatura não foi uma escolha inicial, mas fui me identificando com o decorrer dos semestres" (QA). Conforme salientam Ogushi e Bardagi (2015, p. 34), “a vivência universitária é um período de constante reatualização do posicionamento do estudante frente ao seu processo de escolha."

A literatura (BRANCO, 2015, COULON, 2011; SAMPAIO, 2011; TEIXEIRA et al., 2008) revela que a entrada na universidade significa grande mudança na vida dos estudantes, pois eles precisam se adaptar às novas exigências acadêmicas e pessoais justamente no momento em que suas redes afetivas e de suporte financeiro e emocional estão sendo reconfiguradas. Assim, os primeiros momentos são geralmente de adaptação à nova vida e de busca de superação das dificuldades que se apresentam, como se nota na seguinte fala de Edna: "quando a gente inicia a graduação, chega sem ter o conhecimento de nada, então, até saber como é toda a universidade, como acontece a formação, leva um tempo. E às vezes, a questão de colegas, de amigos, para gente estar mais próxima, a gente não se abre de imediato. E existe a pressão dos professores, então, a gente toma um susto. E aí vem as condições financeiras e no meu caso, que tenho um filho e esposo, tenho que manter a casa, e a gente só consegue ter uma bolsa-auxílio depois" (EP).

Diversos estudos (BRANCO, 2015; COULON. 2011; TEIXEIRA et al., 2008) destacam a importância do primeiro ano na universidade para a integração do estudante à vida universitária, a qual, ocorrendo de forma satisfatória pode contribuir para sua permanência até o término do curso e para o seu sucesso acadêmico. Selecionamos alguns trechos de depoimentos que demostram as dificuldades vivenciadas por boa parte dos estudantes. Por exemplo, Fox enfatiza o fato de morar longe da família e problemas de saúde: "eu tive dificuldade de me adaptar. A pessoa chega nova, nunca morou fora, você tem um baque com a faculdade, que é diferente, e aí veio química. Eu fiquei um pouco adoentado, viajava muito para o médico e acabei faltando muita aula e perdi em química, e química é pré-requisito e atrasou muito" (EP). Enquanto Caio sentiu baixar a confiança em si devido ao seu desempenho acadêmico: "no primeiro semestre foi um baque, eu tive 
que ir para final, nunca tinha ido para recuperação na minha vida, então, pensei em desistir de uma disciplina da cadeia dos grandes pré-requisitos. Ir para a final para mim foi um desespero, queria desistir, mas aí eu conversei com algumas pessoas e percebi que isso era normal, não media inteligência nem capacidade de ninguém, então, aí permaneci no curso" (EP). Já Luna sentiu dificuldades com o ritmo intenso da universidade: "fui me sentindo muito sufocada dentro da faculdade, muita coisa, professor passava trabalho, mais trabalho, mais trabalho. Foi logo no início eu me senti sufocada, aí veio na mente que foi minha segunda opção, eu não tenho afinidade. Será que é isso que eu quero? É hora de desistir e tentar outra coisa? Aí fui para casa, larguei tudo aqui fui para casa. Aí sentei e conversei com minha tia. Ela falou: 'não, termina o semestre'. Acabei desistindo de uma disciplina para diminuir a carga para ver se eu continuava no curso e aí graças a Deus, eu continuei" (EP).

Para os estudantes com deficiência, há ainda outros desafios, conforme nos conta Lara: "difícil, a palavra é essa: difícil. Desde que eu me entendo por gente, estudar é difícil. Claro que minha vida pessoal também interfere, por que eu tive paralisia cerebral, e eu tenho uma certa dificuldade de aprendizagem. É tanto que eu não... às vezes, eu não termino ao mesmo tempo que os outros" (EA).

Notamos que as características pessoais e as particularidades das histórias de vida de cada estudante podem se constituir tanto como aspectos facilitadores quanto como desafios cotidianos e, até mesmo, como dificuldades para a permanência desses alunos na universidade. Porém, esses não são os únicos fatores a serem considerados, pois, como destaca Coulon (2011, p. 1239), esse momento de transição é acompanhado "por mudanças importantes na sua relação com o saber: as regras não são as mesmas, elas são mais sofisticadas, complexas, simbólicas e devem ser rapidamente assimiladas pelos novos estudantes". Isso demostra a importância de a universidade conhecer aqueles que nela ingressam e de promover ações que facilitem a inserção institucional dos recémchegados (SOUZA; SANTOS, 2014).

Segundo Teixeira et al. (2008, p. 197), “a falta de um maior conhecimento sobre o que é a universidade e o que esperar dela, tanto em termos acadêmicos, quanto pessoais, é um fator que pode concorrer para as dificuldades de adaptação". Assim, entendemos que o desconhecimento a respeito das especificidades da licenciatura pode não apenas dificultar a integração dos estudantes, mas também levar à frustação no decorrer do curso. 
Desse modo, os que frequentam o curso por razões outras que não o interesse pelo magistério, podem ter mais dificuldades de adaptação e vir a entender as atividades didático-pedagógicas como um problema. Por exemplo, Teo considerou de forma negativa o fato de o curso apresentar uma "hiper focalização em critérios pedagógicos em detrimento do científico" (QA), uma clara manifestação de quem gostaria de estar em um curso de bacharelado e não em um de formação docente.

As tensões entre licenciatura e bacharelado nos cursos de ciências biológicas, a posição secundária que muitas vezes a licenciatura toma nesse contexto e as implicações disso para a formação docente já são debatidas a tempos (DINIZ-PEREIRA, 1996), mas continuam permeando a formação dos futuros professores, com consequências para a sua autoimagem pessoal e sua identidade profissional (BRANCO, 2015; BRANDO; CALDEIRA, 2009; SOUZA; CHAPANI, 2017).

\section{2 - O curso: identidade, prazer, desafios, estresse, amizades}

Diversos estudantes citaram as dificuldades apresentadas pelo currículo para seu desenvolvimento acadêmico. As disciplinas de exatas, que se situam no início do curso, encontram-se em destaque, principalmente porque algumas delas são pré-requisitos de longas cadeias de disciplinas, conforme narrou Luna: "logo quando eu entrei, me deparei com física, matemática e química, que são as disciplinas que mais reprovam. Aquilo foi um baque para mim e acabei perdendo em matemática e química" (EP).

Por outro lado, as disciplinas específicas das ciências biológicas são, de forma geral, entendidas como fator de interesse, Luna narrou: "eu sempre me identifiquei com essas disciplinas área de zoologia, eu gosto da parte de vertebrados, de invertebrados. Então, isso acaba motivando a gente, quando a gente se identifica com a disciplina, a gente se identifica com o jeito do professor levar a disciplina e isso ajuda bastante (EP). Aiton disse que "teve muita disciplina que foi de acordo com que imaginava que seria, principalmente as disciplinas de campo, sempre abordava coisas que eu via na televisão, no trabalho do biólogo... sempre tem essas questões de descoberta, de trabalhar com as funções dos animais, funções das plantas, a pesquisa em laboratório...” (EP).

No entanto, alguns estudantes fizeram críticas à organização curricular do curso e a abordagem didática de certas disciplinas, como exemplificado na fala de Caio: "para mim, o currículo precisa ser revisto, não só nessa redistribuição, mas também em outras 
disciplinas para tentar melhorar esse ensino. E também os professores precisam mudar a sua didática e entender que não é necessário autoritarismo e inflexibilidade que muitos ainda têm, como uma forma de reprimir o aluno [...]. Essa questão da base teórica, tem muito conteúdo, muita coisa que realmente, na prática, foge um pouco".

Um espaço importante a ser considerado na formação profissional e a constituição da identidade docente é o estágio curricular supervisionado, obrigatório para os alunos de licenciatura. Pimenta e Lima (2012) atribuem ao estágio papel estruturador desses cursos, pois ele não apenas promove o desenvolvimento de competências e habilidades próprias do magistério, mas se constitui em espaço privilegiado, onde os estudantes passam a ser ver como profissionais, atribuindo sentido ao fazer docente.

As manifestações dos participantes com respeito ao estágio curricular foram diversas. Alguns apresentaram preocupação, principalmente com relação aos que ocorrem no último ano, em que o licenciando deve assumir a regência da classe, conforme nos contou Luna "no estágio foi meio que... não foi um baque mas, você se sente assim: 'agora é só eu e a turma não tem nenhum colega do lado para ajudar, não tem professor, sou só eu e a turma'. Mas, mesmo assim foi tranquilo e fui me identificando, gostei até do estágio, mesmo com esse choque de realidade que a gente acaba tendo" (EP). O momento do estágio configura-se como de grande importância na assunção das especificidades do curso de licenciatura, conforme narrou Iraldo: "eu decidi mergulhar na licenciatura com o estágio de regência, então, hoje, eu to me dedicando muito a essa questão da licenciatura e não tanto ao laboratório" (EA). Outros alunos destacaram a importância dessa experiência formativa na definição da docência como uma carreira possível e até mesmo desejável. Aiton, por exemplo, disse que: "foi um curso que eu não entrei com o entendimento de ser formação de professor, mas foi uma área que me chamou atenção, acho que pelas oportunidades de estágio, com regência $e$ coparticipação. Acho que eu fosse para atuar em sala de aula, eu atuaria com certeza com a maior dedicação, apesar de não ser algo que eu que seja meu foco principal” (EP), enquanto Edna assim se expressou: "optei pela licenciatura para conseguir um emprego, mas no decorrer do curso aprendi a amar a licenciatura. No estágio que estou fazendo, me sinto feliz em estar no espaço escolar" (QA).

Além das disciplinas e do estágio, a instituição oferece oportunidade para que os estudantes desenvolvam atividades não obrigatórias relacionadas à sua formação. Dentre 
os participantes da pesquisa, $83 \%$ já se envolveram em alguma atividade extracurricular e todos se referiram positivamente à experiência. Os que não participaram alegaram majoritariamente falta de tempo, como podemos observar no depoimento de Kátia: "sou de outra cidade e só estou à noite na UESB, para as aulas, e a maioria dessas atividades são realizadas no vespertino, então, eu fico impossibilitada" (QA) e de Daniel: "sei de diversos projetos e gostaria muito de participar, mas como trabalho durante o dia, não consigo participar de nenhuma atividade extracurricular" (QA).

Aqueles que têm disponibilidade buscam por atividades extracurriculares para ampliar seus conhecimentos e experiências, bem como alargar as possibilidades de carreira futura. Leide, por exemplo, é uma estudante trabalhadora que não mora em Jequié, de modo que sua participação nessas atividades fica restrita, como ela conta: "até tentei participar do Pibid, mas não foi possível, pois moro fora e teria que gastar com passagem e abandonar o trabalho, mas participo sempre das Semanas de Biologia, Workshop de Genética, e outros eventos que caibam no meu tempo" (QA). Marta, ao contrário, tem disponibilidade para se envolver em diversas atividades: "participei de um Projeto de Extensão, como bolsista no $2^{\circ}$ semestre, este projeto era voltado ao Ensino de Botânica, como estava iniciando o curso, foi uma experiência muito boa para conhecer o campo da pesquisa-extensão. Atualmente faço parte do Pibid” (QA). Não apenas atividades de ensino, pesquisa e extensão atraem os licenciandos, mas eles se engajam também nos movimentos estudantis e nas representações discentes nos órgãos colegiados, como é o caso de Iraldo: "Quando eu cheguei aqui, eu me deparei com pessoas politizadas, com pessoas que entraram nesse universo e que despertaram em mim o interesse de viver a universidade e tudo o que ela poderia me oferecer, então, eu já entrei no DCE [Diretório Central dos Estudantes]" (EA).

A participação nessas atividades reforça uma identidade, que pode ser distanciada da docência. Lara, por exemplo, nos contou: "eu iniciei aqui no laboratório, eu quero ser geneticista, alguma coisa que trabalhe com laboratório, eu nunca quis trabalhar com público, eu morro de vergonha, eu queria estar escondida, assim, quietinha” (EP). A fala de Miguel também vai nessa direção: "eu me engajei logo no segundo semestre aqui no laboratório, então, foi uma rápida adaptação. Meu orientador me deu todo o suporte, a gente começou realmente a trabalhar com paleontologia e todos os trabalhos que eu tenho feito são na paleontologia, e aí fui pegando o gosto. Na verdade, inicialmente eu não tinha nenhuma expectativa do curso a não ser formar, mas depois que eu entrei no laboratório, foi bem tranquilo" (EP). Sabemos que as licenciaturas em ciências biológicas 
"propiciam muitas vezes ao aluno identificar-se mais como pesquisador nessas áreas do que como professor ou pesquisador em ensino, apesar da opção no vestibular por um curso de formação de professor" (BRANDO; CALDEIRA, 2009, p.156). Nesse sentido, quando Lara afirmou: "só em último caso vou pra sala de aula" ou Miguel, que ao expor seus planos para depois de se formar, disse: "prefiro fazer uma pós-graduação, aplicada a paleontologia, não penso em nada na educação no momento, mas se tiver que acontecer não vou me sentir mal por isso", fica evidente a opção em segundo plano pela docência, conforme evidenciou Gatti (2010).

No entanto, outras experiências, principalmente com o Pibid, serviram para acender ou reforçar o interesse pelo magistério, como por exemplo, nos conta Ane: "para mim foi uma experiência muito proveitosa, por que foi no Pibid que realmente eu vi que me identificava com a licenciatura, ao atuar em sala de aula, pude observar algumas coisas que irá me servir de exemplo quando eu estiver atuando como professora" (QA).

Dessa maneira, entendemos que as atividades extracurriculares podem se configurar como atividades exploratórias que, conforme Ogushi e Bardagi $(2015,36)$ são "fundamentais para a realização de escolhas profissionais maduras e realistas e favorecem, consequentemente, a entrada no mercado de trabalho de maneira mais segura". Nesse sentido, consideramos importantes as oportunidades presentes na universidade nos campos do ensino, pesquisa, extensão e do movimento estudantil, para que os discentes possam vivenciar diversas possibilidades de inserção social e profissional. Por outro lado, nem todos têm essa chance, especialmente os alunos trabalhadores, de forma que deveriam ser considerados meios de flexibilização curricular que possibilitassem a mais alunos essa participação.

Outro aspecto interessante, que encontramos em diversos depoimento, foi a importância dessas atividades para a permanência no curso, como nos conta Vicente: "um dos motivos que me levou a ficar no curso de biologia, foi que logo no primeiro semestre, a partir de um contato com o monitor de Biologia Celular, eu perguntei a ele sobre o que ele estudava aqui, pesquisava. Aí ele me falou que pesquisava a parte da sexualidade, que era um tema que me atraía muito e eu fiquei interessado, e ele me explicou que existia esse grupo de pesquisa e que eu poderia estar agregando a ele, e eu comecei a participar das reuniões, e fui ficando cada vez mais" (EA). Nesse sentido, Souza e Santos (2014) já destacavam a importância da iniciação científica como lócus para aprendizado do oficio de estudante, colaborando para a afiliação estudantil e a permanência no curso.

O curso tem duração de oito semestres no diurno e nove no noturno, durante esse tempo, alguns alunos engajam-se em diversas atividades, sequencial ou concomitantemente, como exemplificado no depoimento de Iraldo "já fui monitor do 
Workshop de Genética, da Semana de Biologia e do Novembro Azul. Já fui da comissão eleitoral do DCE e do Centro Acadêmico, atualmente sou coordenador geral do DCE e coordenador da Semana da Biologia 2018. Trabalho em um projeto de pesquisa há quase três anos com mimercofauna e interação inseto-planta. Fui monitor de Invertebrados II e atualmente sou monitor de Invertebrados III. Sou conselheiro em diversos órgãos colegiados e representante discente no Colegiado de curso e sou membro de um grupo de pesquisa” (QA).

Como algumas dessas atividades são remuneradas com bolsas, elas acabam se constituindo como um auxílio importante para a permanência do estudante no curso. Iago, nos conta que: "o curso propicia isso, você tem um programa de bolsas, o Pibid, a iniciação cientifica. Por isso que existe hoje a brincadeira de que enquanto você ta na universidade você tem uma remuneração, depois que você sai, você fica desempregado" (EA). O depoimento de Lara também é esclarecedor nesse sentido: "a entrada no Pibid foi incentivador demais, porque eu estava num momento: 'poxa, eu quero trabalhar', eu já tinha passado num concurso, mas não estava trabalhando, eu vendia produtos de beleza, eu sempre procurava alguma coisa pra fazer" (EP).

No entanto, alguns sofrem também pelo acúmulo de atividades, conforme explica Vicente: "nós temos uma grade fechada do curso, e aí as vezes choca alguns horários, e a gente precisa fazer escolhas, às vezes que eu tenho aula dia de sábado, porém eu tenho curso de extensão no mesmo horário, ai eu tenho que ficar conciliando, alternando, um ou outro, pra tentar lidar com tudo". Mesmo quando se trata apenas das disciplinas, as exigências do curso podem ser estressantes, conforme podemos notar no depoimento de Maura: "a gente tá no quinto semestre, a gente tá enlouquecido, a gente tá pegando oito matérias, era pra eu pegar nove e aí eu desistir de uma. É muita coisa corrida, sendo que podia a gente tá vendo as coisas mais detalhadas, de maneira mais gostosa, mais prazerosa, com menos matéria, pra gente se preocupar menos, porque os professores ficam 'ah vocês ficam muito preocupados com prova'. Gente, é impossível não se preocupar com prova! Porque passa, numa semana, cinco provas, e querem que a gente pense em outras coisas? Não dá! O curso é muito concentrado, quatros anos é impossível a gente, pra mim tinha que ser uns cinco anos, abrir aí um pouco mais a grade, porque isso aí pra gente é muito, muito pesado, a gente fica muito estressado. E o diurno é... nossa! Acho que o noturno deve ser mais tranquilo, pra quem não trabalha né, porque pra quem trabalha deve ser um pesadelo, pra quem não trabalha o noturno é o ideal" (EA). Quando se agregam outras atividades, principalmente aquelas vinculadas a bolsas, ocorre uma maior intensificação das atividades discentes, conforme nos narrou Marta: "onde eu mais me sinto assim... acumulada de coisa, é na iniciação científica, até porque lá eu sou bolsista, então, a rigorosidade é maior. Mas, às vezes, eu me sinto pressionada, 
não vou mentir pra você. E vou ser sincera, eu to me sentindo aliviada esses dias que minha orientadora viajou, porque eu tive tempo de estudar, mas ainda assim, eu não tive um bom rendimento nas disciplinas esse semestre".

Vemos assim, que as manifestações dos estudantes a respeito do curso, se ouvidas e compreendidas pelos gestores, poderiam se constituir como importantes pautas na busca de melhoria do curso. Aspectos como a organização curricular, o sistema de avaliação (e seu próprio significado dentro do curso), as relações entre as atividades curriculares e extra-curriculares, entre outros temas, deveriam ser constantemente debatidos em um processo de avaliação permanente do curso, de modo que as experiências formativas fossem mais significativas e menos estressantes para alunos e professores.

A essas dificuldades acadêmicas, juntam-se outras de caráter pessoal, pois o estudante não é só um aluno, mas também um trabalhador, um pai ou uma mãe, enfim, uma pessoa que integra outros espaços e outras vivências, que podem gerar conflitos com a vida acadêmica, como exemplificado pela fala de Lara: "os professores pensam que você só tem isso, que você não tem trabalho ou você não tem família, você não tem uma vida social... esse tipo de coisa, sabe? (EA). Aspectos da personalidade de cada um também configuram-se como desafios, conforme narrou Jacy: "Eu tive dificuldades, porque eu não estava preparada para dar aula, fazer seminários, eu era muito tímida, mal me expressava direito, ficava recuada no canto, então, eu tive que me esforçar bastante com relação a isso, e logo depois que surgiu o meu problema de saúde, aí eu pensei mesmo em desistir" (EP). A conciliação com o trabalho é particularmente complicada, por exemplo, Ailton disse que: "eu cheguei a trancar o curso por um momento, devido ao trabalho. Surgiu uma oportunidade de um trabalho em outra cidade, então, não teria como conciliar. Mas eu sempre tive aquele pensamento de que eu gostaria de estar voltando para concluir e ter o curso superior" (EP). Outras contingências também interferem na vida acadêmica dos estudantes, por exemplo, Iago nos contou que "no final do primeiro ano eu tive um acidente de carro, acabei saindo do trabalho e aí eu entrei no Pibid. O dinheiro da bolsa por um tempo me ajudou a me manter" (EA).

Nesse contexto, as interações pessoais com colegas, professores e familiares, são essenciais para a vida universitária. Nesse sentido, a família é uma referência muito presente. Ela pode ser a influenciadora na escolha do curso, como nos contou Paola " $a$ licenciatura está presente na minha família e venho me aprofundando para aprender e me tornar futura professora de biologia" (QA). Também foi considerada por alguns estudantes como fundamental para a permanência no curso, conforme destacou Lara: "principalmente minha mãe que é ... meu braço direito...tudo é com ela, minha 
dificuldade, meu lamento, meu choro, minhas alegrias, minhas tristezas". No entanto, a família concorre com o tempo de estudos, como nos relevou Alex: "pela manhã trabalho para sustentar a minha família, a tarde faço Pibid e a noite e sábado a tarde tenho aulas".

Embora a formação profissional seja o objetivo mais evidente de quem ingressa no ensino superior, a vivência universitária estende-se para além disso, pois, a "entrada na universidade implica uma série de transformações nas redes de amizade e de apoio social dos jovens estudantes" (TEIXEIRA et al. 2008, p. 186). Jason, por exemplo, narrou que "como eu moro fora, meus colegas sempre me ajudaram, por exemplo, eu pegava disciplina de manhã, e aí meu colega dizia: 'olha pode dormir lá em casa', as meninas diziam: 'vamos lá para casa almoçar', essas coisas que me ajudaram muito" (EP). A fala de Miguel também é esclarecedora nesse sentido: "é claro que a turma nunca é coesa, sempre tem suas dificuldades e tudo o mais, mas a gente tem também o nosso nicho, aquelas pessoas que realmente estão com você o tempo todo e, às vezes, você deixa de fazer uma coisa e tem uma pessoa pra te cobrir, as vezes você faz pelo outro. Em um curso de quatro anos e meio sempre vai acontecer um percalço ou outro, mas com certeza, as amizades, os colegas, o meu orientador, os professores, tudo isso foi bem relevante no curso" (EP). As relações com os professores também contam positivamente, conforme notamos na fala de Jason: "teve vários professores que sentaram, conversaram, sempre me motivaram mesmo, sabe. Por mais que exigisse conteúdo, mas sempre falava: 'não, as coisas são assim mesmo, devagar, e você vai conseguir alcançar tudo'. Tem que ter um apoio". Porém, essa relação também pode ser conflituosa e desestimulante, como nos contou Caio: "tiveram uns professores que eu disse assim: 'nossa, eu poderia desistir, eu não quero’. Mas eu permaneci, porque não era alguma palavra desestimulante desses professores que iriam mudar minha vida, pelo contrário, seria incentivo para permanecer no curso e na vida acadêmica, então eu deixei, eu tirei esse poder e autoridade que eles tinham sobre mim, pelo menos nessa perspectiva de desistir" (EP). A dimensão didática influencia nessa relação, conforme destacou Luna: "tem professor que não é motivador, que chega na sala joga o conteúdo e a gente acaba não aprendendo nada” (EP).

O bom relacionamento entre os estudantes e entre eles e seus professores é considerado um fator importante para a satisfação acadêmica dos discentes e para sua permanência no curso até a conclusão (SCHLEICH; POLYDORO; SANTOS, 2006; 
BARDAGI; HUTZ, 2012), portanto é um aspecto que as Instituições de Ensino Superior devem estar atentas a fim de favorecer um ambiente acadêmico mais positivo. Desse modo, entendemos ser importante conhecer e valorizar as vivências e experiências pelas quais passam o licenciando em sua formação universitária, pois, "não é possível reduzir a vida escolar às dimensões racionais, nomeadamente porque uma grande parte dos atores educativos encara a convivialidade como um fator essencial e rejeita a centração exclusiva nas aprendizagens acadêmicas" (NÓVOA, 1992, p. 14).

\section{CONSIDERAÇÕES FINAIS}

Parafraseando Nóvoa (1992), podemos dizer que o estudante é antes de tudo uma pessoa. A abordagem que utilizamos nos permitiu conhecer a diversidade de histórias de vida e de relações que se estabelecem entre essas existências singulares e o curso de licenciatura em ciências biológicas dessa universidade pública no interior da Bahia.

Notamos também o dinamismo dessas relações que vão se alterando no decorrer da vida universitária: gostar/não gostar do curso, querer/não querer ser professor, interessar-se/não se interessar pode determinadas áreas. Conta muito nessas alterações não apenas as experiências vivenciadas na relação com o conhecimento biológico e educacional e com as práticas científicas e pedagógicas, mas também as interações pessoais desenvolvidas com colegas, professores e a família.

\section{REFERÊNCIAS}

ALMEIDA, L. S.; SOARES, A. P. C; FERREIRA, J. A. G. TRANSIÇÃO E ADAPTAÇÃO À UNIVERSIDADE Apresentação de um Questionário de Vivências Académicas (QVA). Psicologia, v. XIV, n. 2, p. 189-208, 2000.

ANDRÉ, M. et al. Estado da arte da formação de professores no Brasil. Educação \& Sociedade, ano XX, no 68, p. 301-309, Dez. 1999.

ASSIS, A. de; OLIVEIRA, A. de. Vida universitária e Saúde Mental: Atendimento às demandas de saúde e Saúde Mental de estudantes de uma universidade brasileira. Cadernos Brasileiros de Saúde Mental, v. 2, n. Dez. 2011. 
BARDAGI, M. P.; HUTZ, C. S. Rotina acadêmica e relação com colegas e professores: impacto na evasão universitária. PSICO, Porto Alegre, PUCRS, v. 43, n. 2, p. 174-184, abr./jun. 2012.

BRANCO, A. L. C. O processo de escolha de estudantes universitários pelo curso de licenciatura em Ciências Biológicas e a escassez de professores de Biologia no Ensino Médio: possíveis relações (Dissertação de Mestrado) Programa de Pós-graduação em Educação da Universidade Federal de Viçosa - UFV: Viçosa, 2015.

BRADO, F. R.; CALDEIRA, A. M. A. Investigação sobre a identidade profissional em alunos de licenciatura em ciências biológicas. Ciência \& Educação, v. 15, n. 1, p. 15573, 2009.

BREMM, D.; GÜLLICH, R. I. C. Processos de investigação-formação-ação decorrentes de narrativas em ciências de professores em formação inicial: com a palavra o PIBID. REnCiMa, v. 9, n.4, p. 139-152, 2018.

COULON, A. O ofício de estudante: a entrada na vida universitária. Educ. Pesqui., São Paulo, v. 43, n. 4, p. 1239-1250, out./dez., 2017.

DINIZ-PEREIRA, J. E. A formação de professores nos cursos de licenciatura: um estudo de caso sobre o curso e ciências biológicas da Universidade Federal de Minas Gerais. Dissertação (mestrado). Faculdade de Educação. Universidade Federal de Minas Gerais. Belo Horizonte: UFMG, 1996.

FERREIRA, V. S. As especificidades da docência no ensino superior. Revista Diálogo Educacional, v. 10, n. 29, p. 85-99, jan-abr, 2010.

GASTAL, M. L. A; AVANZI, M. R. Saber da experiência e narrativas autobiográficas na formação inicial de professores de biologia. Ciênc. Educ., Bauru, v. 21, n. 1, p. 149$158,2015$.

GATTI, B. A. Atratividade da carreira docente no Brasil. In: Fundação Victor Civita. Estudos e pesquisas educacionais. São Paulo: FCC, 2009, v. 1, n. 1.

formação de professores no Brasil: características e problemas. Educ. Soc., Campinas, v. 31, n. 113, p. 1355-1379, out.-dez. 2010.

GOMES, M. F. C.; MORTIMER, E. F. Histórias sociais e singulares de inclusão/exclusão na aula de química. Cadernos de Pesquisa, v. 38, n. 133, jan./abr. 2008. 
LUDKE, M.; ANDRÉ, M. E. D. A. Pesquisa em Educação: abordagens qualitativas. São Paulo: E.P.U, 2012.

MASSI, L. VILLANI, A. Contribuições dos estudos de perfil dos graduandos: o caso dos cursos de licenciatura e bacharelado em Química da UNESP/Araraquara. Revista Brasileira de Pesquisa em Educação em Ciências, v. 14, n. 1, 2014.

MAZZETTO, S. E.; SÁ CARNEIRO, C. C. B. Licenciatura em química da UFC: perfil socioeconômico, evasão e desempenho dos alunos. Quim. Nova, v. 25, n. 6B, p. 12041210, 2002.

MORAES, R. GALIAZZI, M. C. Análise Textual Discursiva. 2. ed. Ijuí: Unijuí, 2011. NÓVOA, A. (org.). Vidas de professores. Porto: Editora Porto, 1992.

OGUSHI, M. M. P.; BARDAGI, M. P. Reflexões sobre a relação estudante-universidade a partir de uma experiência de atendimento em orientação profissional. Extensio: R. Eletr. de Extensão, Florianópolis, v. 12, n. 19, p.33-50, 2015.

PIRES, E. F.; NUNES, D. F.; SANTANA, L. L.; SILVA, K. A. C. P. Quem quer ser professor no Brasil: um estudo preliminar a partir de dados socioeconômicos de estudantes de cursos de formação inicial. In: MARTINEZ, A.; OSORIO, L. M.; VARGAS, J. S. A. Reflexiones sobre la Educacion em Iberoamerica. Universidad Autónoma de Bucaramanga, Bucaramanga (Colombia), 2014.

PIMENTA, S. G.; LIMA, M. S. L. Estágio e docência. 3. ed. São Paulo: Cortez, 2012.

SAMPAIO, S. M. R. (org.) Observatório da vida estudantil: primeiros estudos. Salvador, Edufba, 2011.

SCHLEICH, A. L. R.; POLYDORO, S. A.; SANTOS, A. A. A. Escala de satisfação com a experiência acadêmica de estudantes do ensino superior. Avaliação Psicológica, v. 5, n. 1, p. 11-20, 2006.

SLONGO, I. I. P; DELIZOICOV, N. C.; ROSSET, J. M. A formação de professores enunciada pela pesquisa na área de educação em ciências. Alexandria Revista de Educação em Ciência e Tecnologia, v.3, n.3, p.97-121, nov.2010.

SOARES, S. R.; CUNHA, M. I. Formação do professor: a docência universitária em busca de legitimidade. Salvador: Edufba, 2010. 
SOUZA, A. S.; CHAPANI, D. T. Tensões entre licenciatura e bacharelado inscritas na participação de estudantes de ciências biológicas em grupos de pesquisa. In: XII COLÓQUIO NACIONAL E V COLÓQUIO INTERNACIONAL DO MUSEU PEDAGÓGICO. Anais....Vitória da Conquista, UESB, 2017.

SOUZA, G. K. A.; SANTOS, D. B. R. Os "novos" universitários e os (des) caminhos para a afiliação estudantil e a permanência. Revista Olhares Sociais, v. 03, n. 02 p. 68$85,2014$.

TARDIF, M.; RAYMOND, D. Saberes, tempo e aprendizagem do trabalho no magistério. Educação \& Sociedade, ano XXI, n 209, p. 209-244, dezembro 2000.

TEIXEIRA, M. A. P., et al. Adaptação à universidade em jovens calouros. Revista Semestral da Associação Brasileira de Psicologia Escolar e Educacional (ABRAPEE), v. 12, n. 1, p. 185-202, Janeiro/Junho, 2008.

UNIVERSIDADE ESTADUAL DO SUDOESTE DA BAHIA - UESB. Proposta de renovação do reconhecimento do curso de Licenciatura em Ciências Biológicas. Jequié, Bahia, 2011

VASCONCELOS, S. D; LIMA, K. E. C. O professor de biologia em formação: reflexão com base no perfil socioeconômico e perspectivas de licenciandos de uma universidade pública. Ciência \& Educação, Bauru, v. 16, n. 2, p. 323-340, 2010. 